\title{
Digestive Oncology in the COVID-19 Pandemic Era
}

\author{
Mariana Brito ${ }^{a}$ b Ana Laranjo $^{c}$ Júlia Sabino $^{a}$ Carla Oliveira $^{a}$ Irina Mocanu ${ }^{a}$ \\ Jorge Fonseca, ${ }^{a, b}$ \\ ${ }^{a}$ Department of Gastroenterology, Hospital Garcia de Orta, Almada, Portugal; b PaMNEC, Grupo de Patologia \\ Médica, Nutrição e Exercício Clínico, CiiEM, Centro de Investigação Interdisciplinar Egas Moniz, Monte da Caparica, \\ Portugal; ' ${ }^{\circ}$ epartment of Gastroenterology, Hospital do Espírito Santo de Évora, Évora, Portugal
}

\section{Keywords}

Digestive oncology · Digestive cancer · Colorectal cancer · COVID-19 P Pandemic

\section{Abstract}

Introduction: Since the rise of the COVID-19 pandemic there has been widespread concern regarding the possible delay in the diagnosis/treatment of cancer patients. We aimed to assess the impact of the COVID-19 pandemic on the diagnosis, treatment, and outcome of patients with digestive cancer. Methods: This was a retrospective study including patients with an inaugural digestive cancer diagnosis discussed for the first time at our center during the weekly digestive oncology reunion (DOR) meeting. The study group was enlisted from March to August 2020, and a control group was sourced from the equivalent period of 2018. Patients with a previous digestive cancer diagnosis/discussion in the DOR were excluded. The following data were collected: demographics, referral origin, tumor staging, first DOR discussion timing, treatment, and outcome. Results: A total of 235 patients were included: 107 in the study group $(65.4 \%$ male, mean age 71.59 years); 128 in the control group ( $54.7 \%$ male, mean age 68.16 years). The mean number of clinical discus-

karger@karger.com www.karger.com/pjg

Karger"

BOPEN ACCESS
(C) 2021 Sociedade Portuguesa de Gastrenterologia Published by S. Karger AG, Basel

This is an Open Access article licensed under the Creative Commons Attribution-NonCommercial-4.0 International License (CC BY-NC) (http://www.karger.com/Services/OpenAccessLicense), applicable to the online version of the article only. Usage and distribution for commercial purposes requires written permission. sions per week was higher in 2018 ( 13.65 vs. 10.67, $p=0.040$ ), without a difference in the mean number of patients discussed for the first time (inaugural diagnosis) between groups $(p=0.670)$. In the 2020 study group, more patients were referred to DOR from the emergency room (ER), fewer from the outpatient clinic/hospital wards $(p<0.001)$, and more were referred after urgent surgery $(p=0.022)$. There was no difference in the mean waiting time from diagnosis to first DOR discussion ( $p=0.087$ ). Tumor staging in colorectal, gastric, and esophageal cancer was not significantly different between the groups ( $p=0897, p=0.168$, and $p=$ $0.717)$. More patients in the study group presented with stage IV pancreatic cancer $(p=0.043)$. There was no difference in the time span from DOR until the beginning of neoadjuvant chemotherapy $(p=0.680)$ or elective surgery $(p=$ 0.198 ), or from surgery until adjuvant chemotherapy ( $p=$ $0.396)$. Also, there was no difference in 30-day mortality from the first DOR date between the groups $(p=0.742)$. Conclusion: During the COVID-19 era there was a reduced number of clinical discussions in the DOR, but the number of debated patients with an inaugural digestive cancer diagnosis was similar. In the study group more patients were referred to DOR from the ER, and were referred after urgent surgery, suggesting a delayed demand for clinical attention. Study 
group patients were not significantly affected by the pandemic regarding timely DOR discussion, beginning of treatment, or 30-day mortality, reflecting the maintenance of the quality of care for digestive cancer patients.

(c) 2021 Sociedade Portuguesa de Gastrenterologia Published by S. Karger AG, Basel

\section{Oncologia Digestiva na Era COVID}

\section{Palavras Chave}

Oncologia digestiva - Cancro digestivo - Cancro colorretal . COVID-19. Pandemia

\section{Resumo}

Introdução: Desde o início da pandemia por COVID-19, desenvolveu-se a preocupação com o possível atraso no diagnóstico/tratamento dos doentes oncológicos. O nosso objetivo foi avaliar o impacto da pandemia no diagnóstico, tratamento e prognóstico dos doentes com cancro digestivo. Métodos: Estudo retrospetivo, incluindo doentes com diagnóstico inaugural de cancro digestivo, discutidos pela primeira vez na reunião semanal de oncologia digestiva (ROD) do nosso hospital, de Março-Agosto 2020 (grupo de estudo) e do período equivalente de 2018 (grupo controlo). Excluídos doentes com diagnóstico prévio de cancro digestivo/discussão prévia na ROD. Colheram-se: dados demográficos, origem da referenciação, estadio tumoral ao diagnóstico, data da primeira discussão na ROD, tratamento e prognóstico. Resultados: Incluídos 235 doentes, 107 no grupo de estudo (65.4\% homens, idade média 71.59), 128 no grupo controlo (54.7\% homens, idade média 68.16). Número médio de discussões clínicas semanais na ROD foi superior em 2018 (13.65 vs. $10.67, p=0.040$ ). Sem diferença estatisticamente significativa no número de doentes discutidos pela primeira vez na ROD (diagnóstico inaugural) entre os grupos $(p=0.670)$. Mais doentes referenciados à ROD do Serviço de Urgência (SU) em 2020, menos a partir do ambulatório/enfermaria $(p<0.001)$ e mais doentes referenciados após cirurgia urgente em $2020(p=0.022)$. Sem diferença entre os dois grupos no tempo médio de espera desde diagnóstico até a primeira discussão na ROD $(p=$ 0.087). O estadio tumoral do cancro colorretal, gástrico e esofágico não foi significativamente diferente nos dois grupos ( $p=0897, p=0.168$ e $p=0.717$ ). Mais doentes apresentaram cancro pancreático em estadio IV no grupo de estudo ( $p=0.043$ ). Sem diferença no tempo desde ROD até início de quimioterapia neoadjuvante $(p=0.680)$ ou cirurgia eletiva ( $p=0.198)$, nem da cirurgia até quimioterapia adjuvante $(p=0.396)$. Sem diferença na mortalidade aos 30 dias após primeira discussão na ROD nos dois grupos $(p=0.742)$. Conclusão: Durante a pandemia, o número de discussões clínicas na ROD foi inferior, mas o número de doentes com diagnóstico inaugural de cancro digestivo foi semelhante. No grupo de estudo, mais doentes foram referenciados à ROD do SU e mais após cirurgia urgente, sugerindo maior demora dos doentes para procurar atenção médica. Em 2020, os doentes não foram significativamente afetados pela pandemia relativamente à discussão atempada na ROD, início de tratamento ou mortalidade aos 30 dias, refletindo a manutenção da qualidade do suporte clínico aos doentes com cancro digestivo.

(C) 2021 Sociedade Portuguesa de Gastrenterologia Publicado por S. Karger AG, Basel

\section{Introduction}

In December 2019 a new coronavirus (SARS-CoV-2) emerged, responsible for an unprecedented respiratory disease called COVID-19 [1, 2]. This virus rapidly spread worldwide, leading the World Health Organization to declare a pandemic on March 12, 2020 [3]. This pandemic has already caused over one million deaths and brought tremendous suffering and disruption to normal life [4].

In the health system, a large variety of measures were adopted to stop the virus' dissemination, with the postponement of scheduled surgeries, outpatient clinic appointments, and non-urgent treatments and exams in order to minimize the burden of patients on health care facilities overwhelmed with COVID cases [5]. With the reorganization of the hospitals and primary care centers in response to the pandemic, there was significant concern regarding the possible delay in the diagnosis and treatment of other conditions, including oncologic diseases.

Cancer patients represent a priority population in terms of accessibility to health resources since, if left without treatment and adequate surveillance, the prognosis can be fatal. At our hospital, we hold a weekly multidisciplinary digestive oncology reunion (DOR) to discuss the digestive oncologic patients, both initial digestive cancer diagnoses and follow-up patients, in which we define the optimal course of action for each one. This multidisciplinary reunion includes gastroenterologists, surgeons, oncologists, radiotherapists, radiologists, pathologists, palliative care professionals, and nutritionists, in order to provide the best and fastest care for these patients. The 
present study aimed to assess the impact of the COVID-19 pandemic on the diagnosis, treatment, and outcome of patients with digestive cancer managed at our hospital.

\section{Materials and Methods}

Every week, during our hospital's DOR, we perform several clinical discussions of patients with digestive cancer, including first time clinical discussion of patients with an inaugural digestive cancer diagnosis, as well as discussion of follow-up patients. The follow-up clinical discussions include patients who lacked diagnostic exams in the first clinical discussion, patients who underwent neoadjuvant therapy and need to be referred to surgery, patients who underwent surgery and require adjuvant therapy, and patients with disease progression who need to be referred to palliative care. Also, whenever there is a general patient status or tumor staging alteration, we perform another clinical discussion to adjust the optimal management option.

The authors performed a retrospective analysis of patients with an inaugural digestive cancer diagnosis, discussed for the first time in our weekly DOR, from March to August of 2020 (study group) and from the same period of 2018 (control group). The exclusion criteria were: age under 18 years, and a previous digestive cancer diagnosis/discussion in the DOR.

The following clinical data was collected for each patient from the hospital database: age, gender, referral origin, tumor site and staging at diagnosis, time from diagnosis to first DOR discussion, treatment(s), time from DOR to the beginning of treatment, elective versus urgent surgery, and outcome.

Statistical analysis was performed using the Statistical Package for Social Sciences (IBM SPSS ${ }^{\circledR}$ Statistics, version 25.0). Categorical variables are presented as frequencies and percentages and continuous variables as means and SD, or medians and interquartile ranges for variables with skewed distributions. Normal distributions were checked using the Shapiro-Wilk test or skewness and kurtosis. A parametric Independent $t$ test was used to compare normally distributed variables. The $\chi^{2}$ test was used for categorical variables. The Kaplan-Meier curve was used to compare 30-day mortality between the groups. All reported $p$ values are 2-tailed, with a $p$ value $<0.05$ indicating statistical significance.

\section{Results}

A total of 235 patients were included: 107 in the study group and 128 in the control group. In the study group, $70(65.4 \%)$ were males and $37(34.6 \%)$ were females, aged between 23 and 94 years (mean age $71.59 \pm 11.99$ ). In the control group, 70 (54.7\%) were males and 58 (45.3\%) were females, aged between 30 and 92 years (mean age $68.16 \pm 12.63)$. The characteristics of the study population are presented in Table 1.

In total, we performed more clinical discussions during our hospital DOR in 2018 compared to 2020 (total of
Table 1. Characteristics of the study population $(n=235)$
Study group

$(2020 ; n=107)$

\begin{tabular}{lcc}
\hline $\begin{array}{l}\text { Gender, } n(\%) \\
\text { Male }\end{array}$ & $70(65.4)$ & $70(57.4)$ \\
Female & $37(34.6)$ & $58(45.3)$ \\
Age, years & & \\
Mean \pm SD & $71.59 \pm 11.99$ & $68.16 \pm 12.63$ \\
Minimum & 23 & 30 \\
Maximum & 94 & 92 \\
\end{tabular}

$\mathrm{SD}$, standard deviation.
Control group

$(2018 ; n=128)$

$70(57.4)$

$16 \pm 12.63$

92
355 clinical discussions in 2018 vs. 256 in 2020), with a higher mean of clinical discussions per week in 2018 (13.65 vs. $10.67, p=0.040$ ). Nevertheless, there was no statistically significant difference in the mean number of first clinical discussions for patients with an inaugural digestive cancer diagnosis in DOR between both periods $(p=0.670)$. The distribution of total clinical DOR discussions and first clinical discussions for patients with an inaugural digestive cancer diagnosis in both groups is illustrated in Figure 1.

Most patients were referred to DOR from primary care/private institutions in both groups $(45.8 \%$ in the study group and $43.8 \%$ in the control group). More patients were referred from the emergency room (ER) in 2020 (29 vs. $10.2 \%$ ) and fewer from the outpatient clinic (10.3 vs. $18 \%)$ and hospital wards ( 15 vs. $27.3 \%$; $p<0.001)$. Furthermore, a higher number of patients were referred to DOR after urgent surgery in the study group (12 vs. 7; $p=0.022$ ). The origin of referral for both groups is presented in Table 2.

No statistically significant difference was found when comparing the mean wait from diagnosis until the first DOR discussion in both groups (mean 29.52 days in 2018 vs. 41.21 days in $2020 ; p=0.087$ ). Tumor staging at the time of diagnosis for colorectal, gastric, and esophageal cancer was not statistically significant different between the groups ( $p=0897, p=0.168$, and $p=0.717$, respectively). Regarding pancreatic cancer, a higher number of patients in the study group presented with stage IV at the time of diagnosis, compared to the control group, in which $50 \%$ of patients presented with stage II pancreatic cancer at diagnosis $(p=0.043)$. The distribution of the different tumor stages at diagnosis of the most prevalent tumor sites in both groups, and respective $p$ values, are presented in Table 3. 
Table 2. Patients' referral origin to DOR in both groups

\begin{tabular}{lllr}
\hline & $\begin{array}{l}\text { Study group } \\
(2020), n(\%)\end{array}$ & $\begin{array}{l}\text { Control group } \\
(2018), n(\%)\end{array}$ & $p$ value \\
\hline Primary care/private institutions & $49(45.8)$ & $56(43.8)$ & $<0.001$ \\
ER & $31(29)$ & $13(10.2)$ & $<0.001$ \\
Urgent surgery & 12 & 7 & 0.022 \\
Outpatient clinic & $11(10.3)$ & $23(18)$ & $<0.001$ \\
Hospital wards & $16(15)$ & $35(27.3)$ & $<0.001$ \\
\hline
\end{tabular}

DOR, digestive oncology reunion; ER, emergency room.

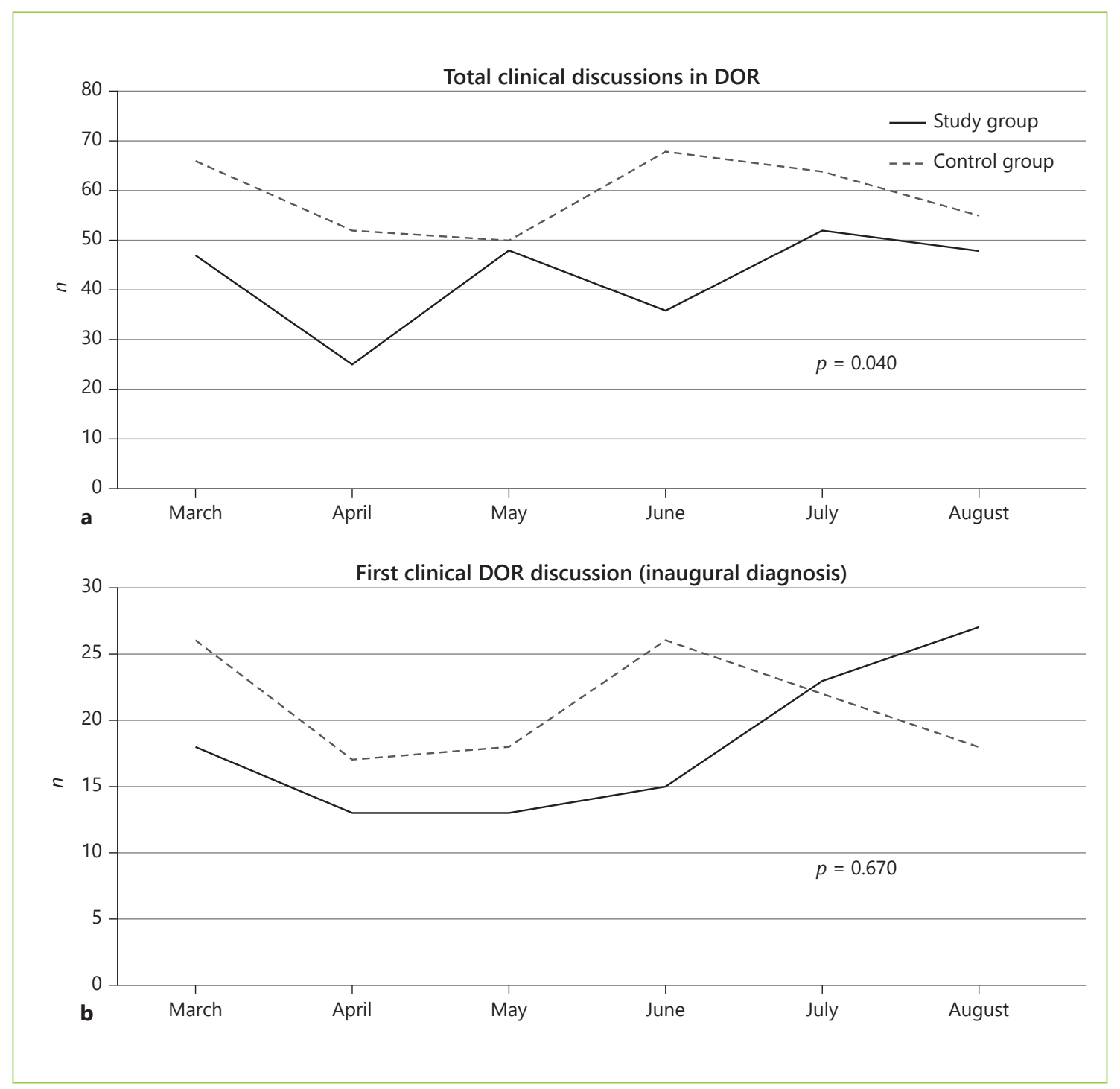

Fig. 1. a Distribution of total clinical DOR discussions in both groups. b Distribution of first clinical discussions for patients with an inaugural digestive cancer diagnosis in both groups. 
Table 3. Distribution of tumor stages at diagnosis of the most prevalent tumor sites in both groups, and respective $p$ values

\begin{tabular}{|c|c|c|c|}
\hline & $\begin{array}{l}\text { Study group } \\
(2020), n(\%)\end{array}$ & $\begin{array}{l}\text { Control group } \\
(2018), \mathrm{n}(\%)\end{array}$ & $p$ value \\
\hline Colorectal cancer & & & 0.897 \\
\hline Stage I & $19(30.6)$ & $18(23.4)$ & \\
\hline Stage II & $14(22.6)$ & $17(22.1)$ & \\
\hline Stage III & $16(25.8)$ & $20(25.9)$ & \\
\hline Stage IV & $13(21)$ & $22(28.6)$ & \\
\hline Total patients & 62 & 77 & \\
\hline Gastric cancer & & & 0.168 \\
\hline Stage I & $4(33.3)$ & $2(8)$ & \\
\hline Stage II & 0 & $6(24)$ & \\
\hline Stage III & $5(41.7)$ & $6(24)$ & \\
\hline Stage IV & $3(25)$ & $11(44)$ & \\
\hline Total patients & 12 & 25 & \\
\hline Pancreatic cancer & & & 0.043 \\
\hline Stage I & $2(14.3)$ & 0 & \\
\hline Stage II & $3(21.4)$ & $6(50)$ & \\
\hline Stage III & $2(14.3)$ & $2(16.7)$ & \\
\hline Stage IV & $7(50)$ & $4(33.3)$ & \\
\hline Total patients & 14 & 12 & \\
\hline Esophageal cancer & & & 0.717 \\
\hline Stage I & 0 & 0 & \\
\hline Stage II & $1(33.3)$ & $2(33.3)$ & \\
\hline Stage III & 0 & $2(33.3)$ & \\
\hline Stage IV & $2(66.7)$ & $2(33.3)$ & \\
\hline Total patients & 3 & 6 & \\
\hline
\end{tabular}

Colon cancer was the most frequent neoplasia in both groups $(42.1 \%$ [ $n=45]$ in the study group and $40.6 \%$ [ $n=$ 52 ] in the control group), followed by rectal cancer ( $15.9 \%$ [ $n=17]$ and $19.5 \%$ [ $n=25]$, respectively). The distribution of tumor sites in both groups is presented in Figure 2.

After a first DOR discussion, the team decided on a curative treatment plan in $64(59.8 \%)$ patients in 2020 and $82(64.6 \%)$ patients in 2018 , whereas 43 patients in 2020 and 45 patients in 2018 were referred for best palliative care. No statistically significant difference was found between both groups considering the proportions of curative and palliative care $(p=0.455)$.

Regarding treatment in the study group: 50 patients (46.7\%) underwent surgery (12 urgent surgery), 3 of which were after neoadjuvant chemotherapy (NCT) and 3 after neoadjuvant chemoradiotherapy (NCRT). In most patients $(84 \%)$ the resection margins were tumor free. Sixteen patients (15\%) required adjuvant chemotherapy (ACT). Nine patients (8.4\%) underwent palliative chemotherapy (PCT) and $2(1.9 \%)$ palliative radiotherapy (PRT). Twenty-two patients (20.6\%) underwent palliative endoscopic procedures. As for the control group, 73 patients (57\%) underwent surgery (7 urgent surgery), 11 of which were after NCRT and 5 after NCT. Also, in most patients $(83.6 \%)$ the resection margins were R0. Twentyfour patients (18.9\%) required ACT; 25 patients (19.7\%) underwent PCT and $1(0.8 \%)$ PRT. Twenty patients (15.7\%) underwent palliative endoscopic procedures. The treatments in both groups are described in Table 4 .

No statistically significant difference was found in the mean period from first DOR discussion until first treatment of NCT (48.86 days in the study group vs. 57.59 days in the control group, $p=0.680$ ). Also, no statistically significant difference was found in the mean period from first DOR until elective surgery (60.81 days in the study group vs. 79.45 days in the control group, $p=0.198$ ). Also, there was no statistically significant difference in the time from surgery until ACT (55 days in the study group and 55.7 days in the control group, $p=0.396$ ).

Eight patients died within 30 days from the first DOR discussion in 2018 and 8 patients died in the same period in 2020 . The 30 -day mortality rate was $6.25 \%$ in the control group and $7.48 \%$ in the study group. There was no statistically significant difference in survival between the groups $(p=0.742)$. Figure 3 illustrates the survival distribution in both groups.

\section{Discussion}

Cancer patients represent a particular population since, from diagnosis, treatment should be initiated as soon as possible due to the risk of disease progression and a poor clinical outcome in most cases. This group of patients frequently need to visit the hospital for treatment and disease surveillance, thus representing a priority to the health care institutions. With the COVID-19 pandemic, health care facilities around the world had to make tremendous efforts and changes to accommodate and treat COVID-19 patients, while attempting to maintain the best support to other non-COVID patients and guaranteeing everyone's safety [6]. At the end of August in Portugal, there were over 14,000 active cases of SARS-CoV-2 infection and over 1,800 deaths due to COVID-19 disease, with a total of 58,000 confirmed cases since March. To the best of our knowledge, there are no national studies regarding the true impact of the COVID-19 pandemic on the diagnosis, treatment, and outcome of cancer patients in general, and particularly in digestive cancer patients.

Colorectal cancer (CC), the most frequent cancer type in our study population, is a very prevalent cancer worldwide [7]. Screening and prevention programs are of ut- 


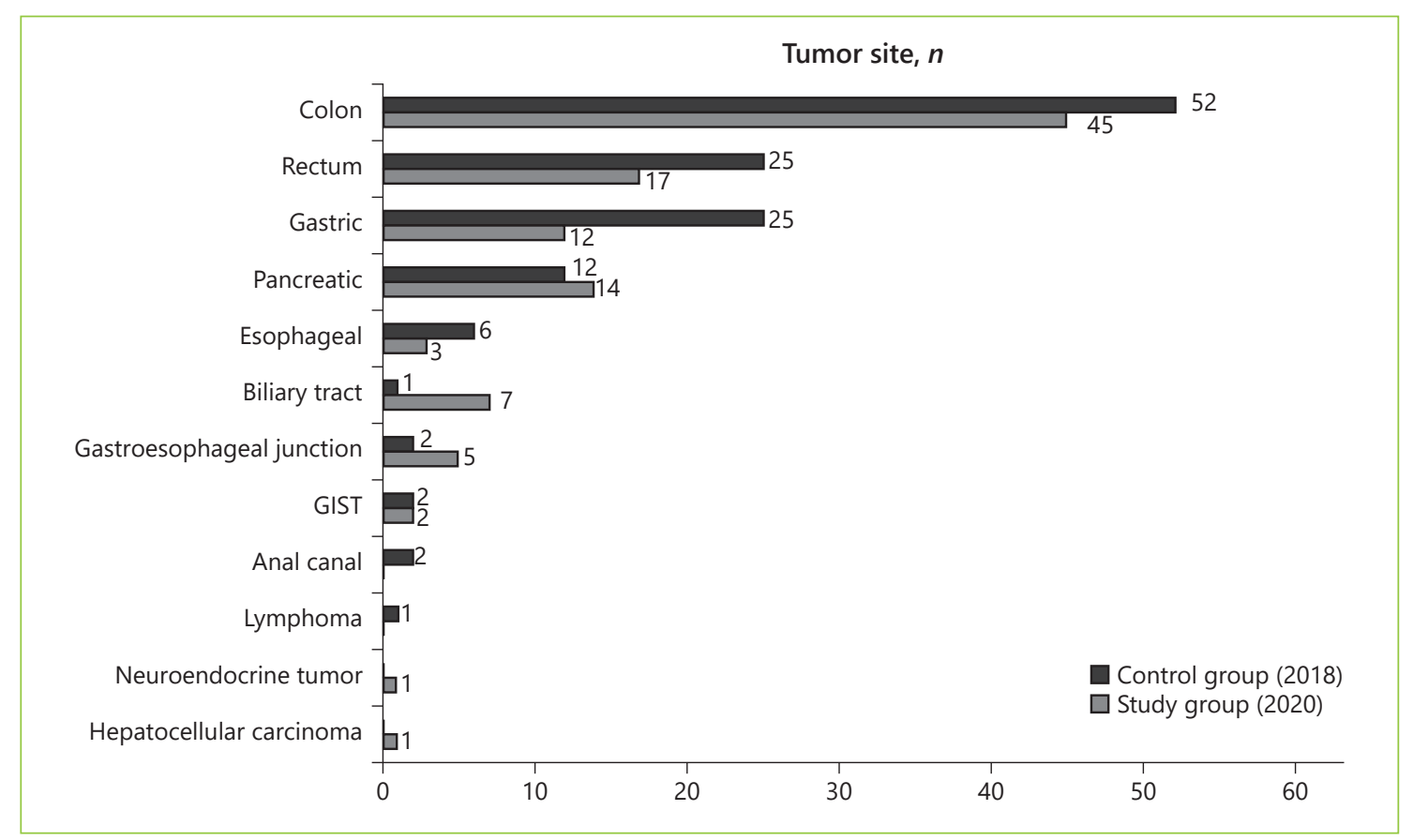

Fig. 2. Distribution of tumor sites in both groups.

most importance to reduce the burden of this condition. In Portugal, prevention of CC greatly relies on primary care centers which alert adult patients, mostly over 50 years old, to undergo screening (either through colonoscopy or occult blood stool samples), and hospitals/private institutions that perform the endoscopic examinations.

On March 18, 2020 a state of emergency was declared in Portugal, leading the health care systems to prioritize urgent visits and delay elective care in primary care institutions, hospitals, and private practices, to mitigate the spread of COVID-19 in health care settings. Private practices in Portugal are responsible for the majority of screening exams. When the state of emergency was declared, they had to suspend non-urgent procedures, at least until this state was lifted. Also, according to the European Society of Gastrointestinal Endoscopy [8], at the beginning of the pandemic outbreak, it was recommended that endoscopic exams should only be performed in urgent or emergent situations. Therefore, non-urgent exams, such as screenings, were delayed. In April 2020, activities slowly began to return to normal, although with several hygienic measures to prevent virus spread.

The present study aimed to assess the impact of the COVID-19 pandemic in the diagnosis, treatment, and outcome of patients with digestive cancer referred to or diagnosed at our center. The total number of clinical dis-
Table 4. Treatment in both groups

\begin{tabular}{lcc}
\hline & $\begin{array}{l}\text { Study group } \\
(2020), n\end{array}$ & $\begin{array}{l}\text { Control group } \\
(2018), n\end{array}$ \\
& $50(46.7 \%)$ & $73(57 \%)$ \\
Surgery & 12 & 7 \\
Urgent surgery & 32 & 50 \\
Elective surgery & 3 & 5 \\
NCT + surgery & 3 & 11 \\
NCRT + surgery & 16 & 24 \\
Adjuvant chemotherapy & 9 & 25 \\
Palliative chemotherapy & 2 & 1 \\
Palliative radiotherapy & 22 & 20 \\
Endoscopic procedure & 13 & 10 \\
Biliary stent & 4 & 2 \\
Esophageal stent & 1 & 4 \\
Gastroduodenal stent & 1 & 1 \\
Colonic stent & 3 & 2 \\
PEG & - & 1 \\
Endoscopic resection & &
\end{tabular}

NCT, neoadjuvant chemotherapy; NCRT, neoadjuvant chemoradiotherapy; PEG, percutaneous endoscopic gastrostomy.

cussions in our hospital's weekly DOR was significantly lower in the pandemic era, although the number of first clinical discussions for patients with an inaugural digestive cancer diagnosis was not significantly different. In 
Fig. 3. Survival distribution in both groups using a Kaplan-Meier curve.

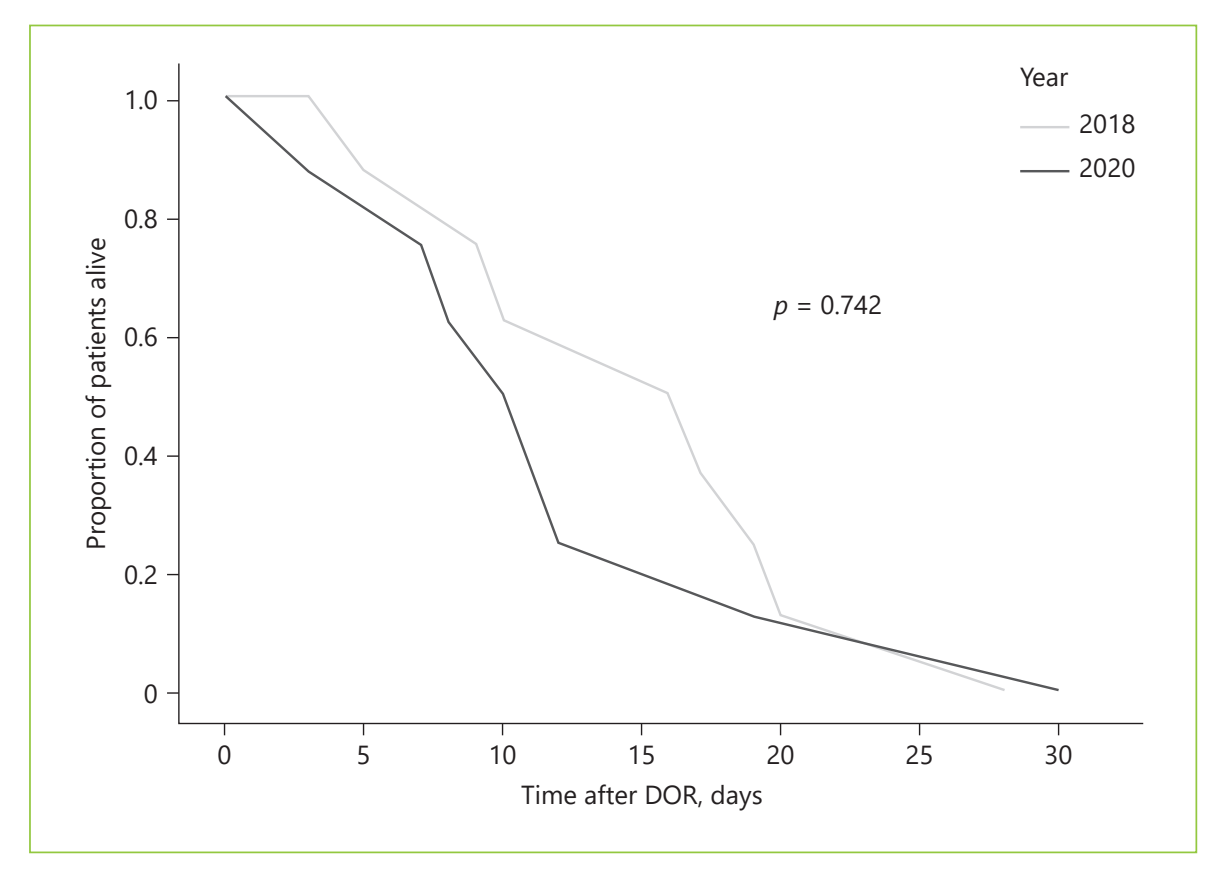

the study group, similarly to the control group, a large percentage of patients discussed at the DOR were referred from primary care/private institutions, reinforcing at least some priority attendance to confirmed/suspected cancer patients. However, more patients were referred from the ER in the pandemic era, probably in relation with an impaired health system response to elective diagnostic exams, and for some fear and delay among patients in seeking medical attention. In fact, a study in the USA showed a reduced ER incidence in some acute life-threatening conditions after the state of emergency declaration, which might be explained by many pandemic-related factors, including fear of exposure to COVID-19, unintended consequences of public health recommendations to minimize non-urgent health care, or stay-at-home orders [9]. In the study group, more CC patients were submitted to urgent surgery due to malignant colorectal obstruction compared with the control group, probably reflecting the delayed diagnosis in these patients.

Regarding the time of DOR discussion, the patients in the study group were not significantly delayed by the COVID-19 pandemic. However, the mean waiting time from diagnosis until first DOR discussion came close to statistical significance, which may be due to a relatively small sample size in the present study.

Tumor staging at the time of diagnosis was not significantly different for colorectal, gastric, or esophageal cancer. However, there was a statistically significant difference regarding the tumor staging of pancreatic cancer, this having been diagnosed at a later stage in the study group, probably reflecting a reduced amount/delay in diagnostic exams performed during the COVID-19 pandemic era. Tumor staging at diagnosis for the residual tumor sites could not be adequately compared between the groups due to the small sample size. The treatment course of digestive cancer patients in our center was not significantly delayed compared to the non-pandemic period, reflecting the maintenance in quality of care to this priority subset of patients.

The COVID-19 pandemic had a negative impact on the total number of patients discussed at our center's DOR, but did not affect the number of patients with an inaugural digestive cancer diagnosis discussed for the first time during our DOR. More patients were referred to DOR from the ER in the pandemic era, with more patients being referred after urgent surgery, and less from outpatient clinic/hospital wards. The patients in the study group were not significantly affected by the COVID-19 pandemic regarding timely DOR discussion, beginning of treatment, or 30-day mortality, again reflecting the maintenance in quality of care to this priority subset of patients.

There is a lot of uncertainty regarding the second wave of COVID-19. The numbers of new infections are rising every day, and the number of patients requiring hospitalization is higher than in the first outbreak. The health services are warning about the imminent collapse of hospitals, tiredness of the health care professionals, and the 
increasing number of in-hospital COVID-19 cases. Maintaining the best care for non-COVID patients during the next COVID-19 waves will be an enormous challenge.

\section{Acknowledgements}

We gratefully acknowledge all the health professionals involved in this study.

\section{Statement of Ethics}

All subjects and/or their legal caregivers were informed and gave their informed consent. This study was approved by our center's Ethics Committee.

\section{Conflict of Interest Statement}

The authors have no conflicts of interest to declare.

\section{Funding Sources}

This work was financed by national funds through the FCT Foundation for Science and Technology, I.P., under the project UIDB/04585/2020.

\section{Author Contributions}

M.B. performed the data curation, statistical analysis, and wrote the manuscript. A.L., J.S., and C.O. were enrolled in data curation. I.M. and J.F. supervised the study and reviewed the manuscript.

\section{References}

1 Wu F, Zhao S, Yu B, Chen YM, Wang W, Song ZG, et al. A new coronavirus associated with human respiratory disease in China. Nature. 2020 Mar;579(7798):265-9.

2 Sifuentes-Rodríguez E, Palacios-Reyes D. COVID-19: the outbreak caused by a new coronavirus. Bol Méd Hosp Infant México. 2020;77(2):47-53.

3 Cucinotta D, Vanelli M. WHO declares COVID-19 a pandemic. Acta Biomed. 2020 Mar; 91(1):157-60.

4 Morens DM, Daszak P, Markel H, Taubenberger JK. Pandemic COVID-19 joins history's pandemic legion. MBio. 2020 May; 11(3):e00812-20.
5 Al-Tawfiq JA, Al-Yami SS, Rigamonti D. Changes in healthcare managing COVID and non-COVID-19 patients during the pandemic: striking the balance. Diagn Microbiol Infect Dis. 2020 Dec;98(4):115147.

6 Al-Shamsi HO, Alhazzani W, Alhuraiji A, Coomes EA, Chemaly RF, Almuhanna M, et al. A practical approach to the management of cancer patients during the novel coronavirus disease 2019 (COVID-19) pandemic: an international collaborative group. Oncologist. 2020 Jun;25(6):e936-45.

7 Dekker E, Tanis PJ, Vleugels JL, Kasi PM, Wallace MB. Colorectal cancer. Lancet. 2019 Oct;394(10207):1467-80.
8 Gralnek IM, Hassan C, Beilenhoff U, Antonelli G, Ebigbo A, Pellisè M, et al. ESGE and ESGENA Position Statement on gastrointestinal endoscopy and the COVID-19 pandemic. Endoscopy. 2020 Jun;52(6):483-90.

9 Lange SJ, Ritchey MD, Goodman AB, Dias T, Twentyman E, Fuld J, et al. Potential indirect effects of the COVID-19 pandemic on use of emergency departments for acute life-threatening conditions - United States, JanuaryMay 2020. MMWR Morb Mortal Wkly Rep. 2020 Jun;69(25):795-800. 